<smiles>C1CCC2(CC1)C1CCCC2C1</smiles>

\section{Abordagem das transformações sócio-espaciais no município de Itaúna do Sul-PR a partir do modelo GTP}

Resumo: O município de Itaúna do Sul, localizado no noroeste do estado do Paraná, durante aproximadamente cinqüenta anos sofreu inúmeras transformações nem seu território. Transformações estas proporcionadas ora pela conjuntura econômica do País, ora pelas políticas públicas local. Este artigo considera estudos realizados em dissertação de mestrado sobre as dinâmicas sócio-espaciais e ambientais do município de Itaúna do Sul utilizando para isso o modelo GTP desenvolvido por Claude e Georges BERTRAND como ferramenta para se estudar o espaço geográfico. A importância da realização desta pesquisa se embasa na possibilidade de se diagnosticar a realidade sócio-espacial e ambiental, os atos político-administrativos que se têm tomado bem como sua importância a realização da sustentabilidade neste território.

\section{Approach of social transformation space and public policy in the city of South Itaúna-PR from model GTP}

\begin{abstract}
Itauna do Sul municipality, located at the northwest of the State of Paraná, during approximately fifty years suffered of countless transformations. Transformations that were caused sometimes by the economic conjuncture of the country, sometimes by the local public policies. This research considers the studies in the Masters about socio spatial and environmental dynamics of the Itauna do Sul municipality, it utilizes the GTP model developed by Georges Claude and Bertrand as an approach to study the geographical. The matter of the realization of this research is based in the possibility to diagnose the social spatial and environmental reality and the political administrative acts that have been taken and also its importance and applicability to the realization of the sustainability in this territory.
\end{abstract}

Lucas César Frediani

Sant'ana*

Messias Modesto dos

Passos* *

* Doutorando em Geografia pela Universidade Estadual de Maringá, na área de análise ambiental

**Professor titular da Universidade Estadual de Maringá

Palavras- chave: Paisagem; Dinâmicas Sócio-Espaciais; Políticas PÚBLICAS; Meio ambiente; Itaúna do Sul - PR.

Key-Words: Landscape; Socio spatial dynamics; Public policies; Environment; Itaúna do Sul, State of Paraná. 


\section{Introdução}

0 presente artigo é resultado da pesquisa realizada com o objetivo de diagnosticar e prognosticar a partir do modelo GTP e de ferramentas como dados primário, secundários, imagens de satélites entre outros, a dinâmica sócio-espacial e ambiental do município de Itaúna do Sul - PR e de que forma as Políticas Públicas locais aplicadas pelos gestores municipais interferem nesta configuração.

Itaúna do Sul, localizada na porção noroeste do estado do Paraná, na microrregião de Paranavaí, constitui-se como um município de instalação recente. Desmembrou-se de Nova Londrina e veio a tornar-se município em 1961. O município é recortado pela rodovia estadual PR - 182, sendo este trecho uma importante ligação entre o noroeste e oeste do estado do Paraná, com o Pontal do Paranapanema/sudoeste do estado de São Paulo. Esta ligação foi dinamizada a partir da construção da ponte sobre o rio Paranapanema pela CESP (Companhia Energética de São Paulo), onde se localiza a usina hidrelétrica (UHE) de Rosana na divisa dos estados de São Paulo e Paraná. A base da economia do município é a agropecuária que, em 2002, representava $45 \%$ do PIB do município. As principais culturas agrícolas são: o café, a cana-de-açúcar, o milho, a mandioca. Destaca-se também, a pecuária de corte e de leite.

O meio ambiente e sua e sua problemática vêm atraindo cada vez mais olhares das mais diversas áreas do conhecimento científico e da mídia. Para o biogeógrafo $\mathrm{G}$. Bertrand, o meio ambiente pode ser definido como um conjunto de elementos externos que rodeiam a sociedade $e$ que com ela interage. Esta "humanização" da problemática ambiental ainda não parece ser bem gerida pelos geógrafos, sobretudo àqueles que insistem na geografia de uma natureza "congelada", à montante da ação antrópica e da problemática ambiental.

Para isso é preciso adentrar a um modelo, que ao mesmo tempo em que agregue toda a complexidade do território, tenha a capacidade de interpretá-lo em suas relações e seja objeto de apoio àqueles que estão diretamente ligados à gestão deste território.

\section{Abordagem teórico-metodológica}

A base teórica desta pesquisa está na aproximação da obra de Claude e Georges. Bertrand: "Uma geografia transversal - e de travessias. 0 meio ambiente através dos territórios e das temporalidades" cuja tradução foi coordenada por Passos (2007), onde a partir dos fundamentos estudados nesta obra, acrescido de cursos que se desenvolveram ao longo da vida acadêmica e da pós graduação, resulta com a proposta de utilizar-se o modelo GTP - geossistema, território e paisagem - que em, síntese, é um modelo tripolar de entrada - estudo - do território para o estudo das dinâmicas sócio espaciais e ambientais dentro do município de Itaúna do Sul-PR, bem como as Políticas Públicas interferem nesta configuração. 0 modelo GTP vem para suprir a necessidade de um método científico mais complexo, para isso, contemplando três abordagens ou entradas.

A primeira delas é o geossistema. Uma entrada de caráter naturalista, contemplando os elementos geo-biofísicos, com seu maior ou menor grau de antropização. Outra entrada é o território onde já são contemplados os fatores socioeconômicos como também a gestão do meio ambiente.

Geografia Ensino \& Pesquisa, v. 16, n.2 p. 117 - 128, maio/ago. 2012

Abordagem dastransformações sócio-espaciais no município de Itaúna do Sul-PR a partir do modelo GTP
Por último, temos a entrada da paisagem, abordando as dimensões socioculturais, a artealização inscrita neste geossistema, neste território.

Segundo BERTRAND estas entradas do GTP, correspondem respectivamente a source = fonte; ressource $=$ recurso; ressourcement $=$ identidade . Abordagem esta que será constante neste artigo, porém não de forma explicitada a que categoria se estará trabalhando, a fim de se obter ao máximo, a análise da dinâmica e funcionamento de nosso recorte geográfico, dentro de sua globalidade. 
Segundo MOREIRA, 2007 e HÖFLING, 2001, entende-se por Políticas Públicas, o conjunto de ações coletivas voltadas para a garantia dos direitos sociais, configurando um compromisso público que visa dar conta de determinada demanda em diversas áreas, sob responsabilidade, em nosso caso de estudo, do Estado onde compete a este as etapas de implementação e de manutenção.

Não é possível a preservação dos "recursos naturais" onde não há a melhoria de condição de vida da população. Com base neste propósito, o desenvolvimento sustentável objetiva diretamente a satisfação das necessidades básicas humanas tais como: alimentação, vestuário, água, moradia e saneamento básico, onde não diz respeito somente ao crescimento econômico.

Entende-se aqui como desenvolvimento sustentável, a exploração dos recursos da Terra atendendo às necessidades do presente, porém sem comprometer a possibilidade das futuras gerações atenderem as suas próprias necessidades, sendo considerado como objetivo a ser alcançado por alguns estudiosos e gestores e tido ainda como utopia por outros, porém fato é inegável nosso instinto de sobrevivência, com busca de soluções diante de problemas que põe em risco o nosso futuro.

Os materiais utilizados nesta pesquisa foram dados primários e secundários pertinentes, bem como a realização de saídas de campo, entrevistas e análise de imagens de satélite e uso de cartas topográficas e temáticas.

Com a utilização do material levantado e do processo metodológico elegido para a presente dissertação, chegou-se a um diagnóstico da área e com o uso deste diagnóstico mais a identificação de processos, chegou-se a um prognóstico para o recorte de estudo, destacando assim, a pertinência de um projeto científico com o propósito de auxiliar/esclarecer a comunidade como um todo e não prevalecer a sua funcionalidade - como de tantos projetos - apenas dentro dos muros da universidade como sendo apenas uma dissertação de conclusão do curso de mestrado em geografia.

\section{Desenvolvimento}

Para efeito de abordagem das políticas públicas em nossa área de estudo, foram levantados materiais junto a EMATER, onde estão documentados uma série de planejamento de política pública aplicada ao setor rural.

O Município de Itaúna do Sul apresenta em sua economia, grande representatividade ligada ao setor agropecuário, apresentando para uma área rural de 4.490 ha, um total de 289 estabelecimentos rurais (média de 15,5 ha por estabelecimento). Para nosso propósito de trabalho nos ateremos às políticas públicas desenvolvidas e aplicadas ao nosso recorte geográfico voltadas basicamente à área rural e ao pequeno produtor.

Desenvolveu-se neste primeiro momento um levantamento de políticas públicas aplicadas à área rural, especificamente do programa estadual "Paraná Rural", "Corredor Caiuá", desenvolvido junto à SEMA e EMATER e FUNRURAL da esfera federal.

O Projeto Paraná Rural, é fruto de uma parceria entre o Governo do Estado do Paraná, durante o governo de Álvaro Dias e o Banco Internacional para a Reconstrução e Desenvolvimento - BIRD. A Secretaria de Agricultura e Abastecimento constituiu um grupo de trabalho encarregado da elaboração do Programa para o pleito junto ao BIRD no ano de 1987, levando à constituição do contrato de empréstimo no ano de 1989 e à direção dos trabalhos até o encerramento do Programa no ano de 1996.

A priori, o projeto era composto por dois subcomponentes, porém por problemas de liberação de financiamento, acabou que limitando-se apenas a um: "Manejo e conservação do solo".

Este projeto baseia-se na organização dos produtores rurais, seccionado por microbacias e na assistência técnica local. Temos então dentro do município duas áreas de microbacia seccionada

Geografia Ensino \& Pesquisa, v. 16, n.2 p. 117- 128, maio/ago. 2012

Sant'ana, L. C. F.; Passos, M. M. 
para este projeto: Microbacia Placa Itaúna cujo plano, do ano de 1992 e Microbacia Zimaré/São Paulo Paraná, cujo plano data o mesmo ano.

Um ponto pertinente contido no documento é a importância dada à fixação do homem no campo. Aárea da microbacia, no passado (leia-se antes da década de 1980), era ocupada em quase sua totalidade pela cultura do café, e a partir do setor cafeeiro, foi sendo substituída pelas atividades pastoris. Destaca-se que para a manutenção e sustentabilidade do pequeno produtor, deve ser implantada a diversificação de culturas - base esta difundida e aplicada junto aos produtores rurais de Itaúna do Sul pela EMATER.

O caráter dessas políticas públicas é fundamentado no subsídio técnico e material ao produtor - principalmente o pequeno - de forma a garantir uma maior sustentabilidade de sua propriedade, gerando, como conseqüência direta, a diminuição dos impactos sobre o meio ambiente e tentar assegurar a permanência deste agricultor com sua família no campo, diminuindo assim os impactos sociais gerados pelo êxodo rural.

O projeto: Paraná biodiversidade - corredor Caiuá/llha Grande, região de Paranavai, é um projeto implementado pelo Governo do Estado do Paraná em conjunto com outras instituições, com o apoio financeiro do Fundo Mundial para o Meio Ambiente através do Banco Mundial a fim de Promover a conectividade entre fragmentos florestais existentes, visando a recuperação e conservação da Biodiversidade, permitindo o aumento dos fluxos biológicos de fauna (terrestre, aérea e aquática) e flora, e conseqüentemente 0 aumento da Biodiversidade, bem como difundir adoção de sistemas agroflorestais (SAF) que reproduzem um sistema ecologicamente estável e oferece retorno financeiro e social.

Em resumo o projeto desenvolvido pela EMATER visa servir como um modelo de desenvolvimento sustentável atingindo os objetivos de promover a conectividade entre os fragmentos florestais através de criação de "trampolim" ecológico, compatibilização dos sistemas produtivos existentes com a conservação da biodiversidade; estimulando a implantação de reserva legal e área de preservação permanente, conforme legislação vigente; realização de práticas de manejo e conservação do solo, que aumente a infiltração da água possibilite maior produção de cobertura vegetal, reduzindo o escorrimento superficial da água e a compactação do solo, visando melhor controle da erosão hídrica e menor degradação ambiental, diminuição da poluição ambiental pela utilização de práticas de manejo e conservação do solo, manejo adequado das explorações e destino correto das águas usadas, no esgoto doméstico e dejetos de animais, serve como unidade demonstrativa de conservação da Biodiversidade e práticas menos impactantes ao meio ambiente.

Uma política pública de âmbito Federal, o Funrural ou Contribuição Social Rural é uma contribuição social destinada a custear a seguridade (INSS). Este tributo é cobrado sobre o resultado bruto da comercialização rural (de 2,3\% a 2,85\%) e descontado, pelo adquirente da produção, no momento da comercialização, diferenciando do trabalhador urbano, onde é descontado da folha de pagamento ou de rendimentos.

Tal política de assistência previdenciária à população rural idosa é de suma importância para 0 entendimento das dinâmicas sócio espaciais e econômica da área de estudo, não por questões quantitativas, senão por demonstrar que pela alta taxa de população idosa vivendo na área rural, grande parte desta depende deste recurso da previdência, praticamente abandonando as atividades agrícolas, mas não o campo. Constatação esta possível a partir de pesquisa de campo e a realização de entrevista com moradores da área rural de Itaúna do Sul.

Tal dado demonstraem um primeiro momento, que não há interesse por parte dos descendentes p. 117 - 128, maio/ago. 2012

Abordagem dastransformações sócio-espaciais no município de Itaúna do Sul-PR a partir do modelo GTP dessa população em continuar na área rural, partindo então à área urbana, trabalhando em sua maioria no setor de prestação de serviços. Em um segundo momento, o processo de arrendamento de terras para cultivo da cana-de-açúcar sendo esta um importante viés de rendimento junto aos benefícios do FUNRURAL para esta população.

Com a crise ambiental e o incentivo à troca da matriz energética - 0 etanol - pelo governo Federal, principalmente por via de liberação de recursos do BNDES, está dinamizando a expansão 
da monocultura da cana-de-açúcar que vem ocupando e "se utilizando" do noroeste do Paraná, dada principalmente pela presença de duas grandes destilarias de álcool: a COPAGRA em Nova Londrina e a Santa Terezinha em Terra Rica que agem como atores da paisagem no município estudado.

As políticas públicas municipais aplicadas à zona rural de Itaúna do Sul, são destinadas principalmente ao pequeno produtor, o que caracteriza também uma preocupação dos gestores na sustentabilidade da pequena propriedade e da permanência das famílias nas áreas rurais porém a cultura canavieira tem avançado principalmente nas médias e grandes propriedades do município, onde estas, ora são sustentadas pela pastagem, ora pela mandioca, associadas à cultura do milho $\mathrm{e}$ do feijão. Por vários fatores que torna insustentáveis as culturas anteriormente citadas, acabam estas terras sendo arrendadas, total ou parcialmente para COPAGRA ou a Santa Terezinha que em forma de contrato, pagam já um valor fixo mensalmente ao proprietário de terra, ou pagam o equivalente à área colhida e valor de mercado da cana-de-açúcar. Tal fato é comprovado ao analisar os dados do IBGE e Ipardes onde mostra um grande aumento da área plantada de cana-de-açúcar a partir de 2004, com uma posterior queda no ano de 2006/2007 e novamente um aumento na área de plantio em 2009.

Se analisado os dados de área plantada de cultura temporária (por tipo de produtos cultivados), registram basicamente dois processos neste período. Primeiro a clara evolução da cultura da cana de açúcar, exceto no ano de 2006, onde segundo produtores rurais, a cana-deaçúcar teve um impacto da queda do preço do Etanol e do açúcar, por isso reduziu a área arrendada pelas usinas, porém voltou ao seu normal crescimento já no ano seguinte.

O segundo processo observado nos gráficos é a crescente tendência a diminuição da diversidade de cultura agrícola temporária desenvolvida no município, predominando o cultivo da cana-de-açúcar e da mandioca.

Um dado pertinente a ser destacado é que no período de 2003 a 2007, não houve substituição da cultura cafeeira pela canavieira, ou seja, o avanço da cana-de-açúcar no município dá-se na grande-média propriedade.

Outra conseqüência das políticas públicas tomadas no município é o crescimento de sua população rural, que foi de $1,13 \%$ no período de 1991 a 2001, conforme dados do IBGE. Tal fato é resultado de políticas públicas locais, destinadas aos pequenos proprietários, sendo, uma vez mantida a estrutura fundiária de pequenas propriedades, facilita a aquisição destas, mesmo por pessoas com menor poder de compra.

\section{Análise do uso da terra}

Segundo ANDERSON et al (1979), o conhecimento no uso e ocupação da terra - ou espaço - é imprescindível a qualquer território, onde o gestor empenha-se em equacionar problemas para assim poder resolvê-los.

O sensoriamento remoto surge então, numa perspectiva de ser uma ferramenta de auxilio à compreensão do espaço geográfico, gerando ações mais eficientes e precisas sob este espaço.

As imagens de satélite constituem a melhor síntese global da paisagem, representando um combinado dos reflexos das sociedades passadas bem como as dinâmicas atuais que ainda estão (re)construindo esta paisagem.

As imagens orbitais utilizadas, é aquela proveniente do satélite LANDSAT-5 TM e para efeito do proposto neste trabalho, utilizou-se das bandas 345 com composição colorida RGB respectivamente, apresentando assim na imagem, cores semelhantes às verdadeiras que compõe a paisagem, facilitando a interpretação da imagem. Segue abaixo alguns padrões - embora não aplicável a todas as imagens - de cores, texturas e formas utilizadas na interpretação e uso dos mosaicos de imagens.

Geografia Ensino \& Pesquisa, v. 16, n.2 p. 117- 128, maio/ago. 2012

Sant'ana, L. C. F.; Passos, M. M. 
Neste sentido, optamos usar como critério o estágio atual e multi-temporal da evolução da paisagem no municio de Itaúna do Sul - PR, sendo então utilizadas as imagens dos anos de 1985, 1995, 2005 e 2009. Vale ressaltar que, para o conhecimento sobre a dinâmica da paisagem, não se satisfaz apenas com o uso do recurso de sensoriamento remoto (Passos, 2008), senão que para isso deve estar este inserido em um conjunto de outros dados, onde a somatória destes faz com que algo tão complexo como é a paisagem tenha seus processos identificados.

As imagens de satélite foram adquiridas junto ao INPE, e após o processo de aquisição, estas imagens passaram pelo processo de composição, classificação e quantificação.

A composição colorida é a atribuição de cores aos canais selecionados. A atribuição de cores é feita com base em três cores, vermelho, verde e azul (Red, Green, Blue) que neste caso foram atribuídas aos canais 543 respectivamente.

O processo de classificação consiste em agrupar em classes áreas da imagem de satélite que sejam homogêneas, como por exemplo, áreas de plantio de cana, de solo exposto, vegetação densa ou áreas urbanas.

A classificação das imagens foi realizada pelo método de classificação por regiões. Inicialmente foi necessária a segmentação da imagem, que fragmenta a imagem em unidades homogêneas, seguindo as características da imagem, como a escala de nível de cinza dos pixels, textura e contraste (Woodcook et al 1994). Em seguida, essas regiões foram associadas às seguintes classes: a) Mata; b) Solo nu; c) Agricultura/pastagem; d) Área urbana. Não foi utilizada a classe "corpo hídrico" pois para efeito de estudo de nosso recorte, esta categoria não tem representatividade na escala de análise, no caso, imagem de satélite, pois grande parte dos ribeirões presentes no recorte espacial apresentam um canal fluvial menor que 10 metros.

A quantificação Por meio da função de medidas de classes do software SPRING foi possivel quantificar a distribuição de cada classe gerada, com os dados fornecidos pelo programa medidos em km² geraram-se gráficos para auxiliar a interpretação das classes da imagem;

Os dados foram agregados em um único gráfico no formado de barras para que fossem comparados, de modo a analisar a distribuição desses elementos ao longo da série histórica de imagens a cada 10 anos, em um período de 30 anos;

A última etapa foi a de análise de todos os dados para a interpretação das informações obtidas.

Foi utilizado nesta etapa do trabalho, alguns mapas gerados pelo projeto CanaSat.

O Projeto Canasat, é um projeto desenvolvido em conjunto por alguns órgãos e instituições com o objetivo de fornece informações sobre a distribuição espacial da área cultivada com cana-deaçúcar na região centro-sul do Brasil utilizando três bases de dados: imagens de satélite geradas pelo programa Canaat, do INPE (base na imagem do satélite Landsat-5 TM); dados levantados pelo IBGE sobre a produção agrícola e pecuária; e relatórios de impacto ambiental produzidos pelas usinas, no qual elas relatam seu plano para produção - quanto vai produzir, quanto de área precisa, em que áreas vão plantar, e o que havia nessas áreas antes do cultivo da cana. Essa análise com dados secundários complementa a análise por satélite.

A Partir da interpolação dos dados, é possível chegar ao diagnóstico de que a classe temática de uso do solo correspondente à agricultura/pastagem abrange toda área do município ocupada com agricultura temporária e permanente além das áreas ocupadas por pastagens (desde que não degradadas onde esta se enquadra na classe "solo nu", como visto anteriormente).

As áreas de agricultura/pastagem do município de Itaúna do Sul, do ano de 1985 a 2005, p. 117 - 128, maio/ago. 2012

Abordagem dastransformações sócio-espaciais no município de Itaúna do Sul-PR a partir do modelo GTP obtiveram um acréscimo de área, dado principalmente sobre áreas de solo nu e em menor proporção sobre áreas de mata, notadamente no período de 1985 a 1995.

No ano de 2009 há um decréscimo desta área em 17\% em relação ao período anterior. Isto se deve, com visto anteriormente, ao aumento da classe "solo nu" ocasionado principalmente pelo 
A cultura do café, impulsora da colonização de Itaúna do Sul, apresentava ainda no ano de 1985, mais da metade de toda área com culturas agrícolas do município. No ano de 1995, já a reflexo da queda acentuada do valor do produto durante toda a década de 1980 e acentuado pela geada que ocorreu no município em 1994 - a partir de relados dos produtores de café - se reduz a apenas $6 \%$ de área agrícola, acarretando no desmonte pequenas propriedades, ocorrendo processo de formação de média/grandes propriedades no município. Porém no ano de 2005 apresenta expressiva recuperação alcançando o índice de 31\% de área agrícola. Tal índice pode ser reflexo das políticas públicas destinada ao pequeno produtor, onde predominantemente está alocada as áreas de cultivo do café no município, localizados em sua maioria na porção norte, onde ainda são preservadas as estruturas de pequenas propriedades dentro do município.

A cultura da mandioca vem em um primeiro momento, a avançar sobre áreas antes destinadas à cultura do café. 0 cambio a esta nova cultura deve-se principalmente ao fato da presença de fecularias nas proximidades de Itaúna do Sul e ao preço convidativo para este tipo de produto (além de comprovado estatisticamente, tal fato já fora antes revelado em entrevistas com produtores do município).

Com a queda do preço da mandioca no mercado e a partir da instalação da usina COPAGRA em Nova Londrina em meados da década de 1990 e de Santa Terezinha em Terra Rica, em 2005, a cultura da mandioca, desenvolvida principalmente na média-grande propriedade passa por um processo de substituição pela cana-de-açúcar.

A cana-de-açúcar, como já referida anteriormente, teve uma expansão acentuada no município nos últimos aproximadamente 15 anos devido à instalação de duas usinas próximas à Itaúna do Sul. Esta cultura avança em médias-grandes propriedades do município, substituindo predominantemente a cultura da mandioca e pastagens degradadas.

A classe temática de uso do solo "Mata" engloba toda área do município recoberta por espécies arbóreas nativas ou exóticas, podendo estas estar alocadas tanto em áreas de APPs, RLs, regulamentadas pelo código florestal $\mathrm{n}^{\circ} 4771 / 65$ (vide anexo), quanto em áreas destinadas à silvicultura.

No período de 1985 a 1995 houve perda expressiva de áreas florestadas, porém em averiguação em imagem sintética do mesmo período indica que esta perda ocorreu principalmente da degradação de relictos de mata ainda existente no município, não sendo contribuinte para este dado a degradação da mata ciliar neste período já que este processo esta à jusante, quando ocorreu o processo de colonização e expansão da cultura cafeeira no município, seguindo o molde implantado pela CTNP no norte do Paraná

Porém a evolução da área de mata entre os anos de 2005 e 2009 indica uma política atuante junto aos produtores rurais de preservação e recuperação da área de preservação permanente, atendendo assim a legislação vigente.

\section{Prognóstico das dinâmicas sócio-espaciais e ambientais}

Para a construção do prognóstico no município estudado, houve uma reflexão a partir de dados secundários, empíricos - entrevistas com moradores e gestores municipais e de empresas - e de imagens de satélite.

O uso das imagens de satélite para constatação da atual forma de uso do solo no município de Itaúna do Sul foi de grande relevância, pois além dos dados (secundários e empíricos) que demonstram os processos ocorrentes na construção da paisagem no município, houve 0 uso das imagens de satélite para interpretar os processos de territorialização e de espacialização.

Como esboço na tentativa de se espacializar um prognóstico de uso e ocupação do solo do município de Itaúna do sul, frente ao avanço da cana-de-açúcar no município, produziu-se uma carta, onde foram destacadas as principais áreas do município onde se prognosticou as dinâmicas sócio-espaciais e ambientais.

Geografia Ensino \& Pesquisa, v. 16, n.2 p. 117-128, maio/ago. 2012

Sant'ana, L. C. F.; Passos, M. M. 
Destacaram-se as áreas onde a cultura da cana-de-açúcar é desenvolvida para um prognóstico de curto/médio prazo. Esta cultura passa a ocupar aproximadamente $70 \%$ do município, onde se destacam algumas áreas:

- avanço da cana-de-açúcar frente à área antes destinada às pastagens e cultura da mandioca. Característica da estrutura fundiária da área é de grandes propriedades. A lógica de ocupação da área pela cana-de-açúcar dá-se também pelo fácil escoamento da produção, pois esta área é atravessada pela rodovia PR-182.

Embora a área junto ao ribeirão Água da Abelha apresente todos os indicativos para ser uma possível área de avanço da cana-de-açúcar, a mesma não foi prognosticada, pois é nesta localidade que encontramos maior extensão dos processos de degradação no município, a mais extensa área com aptidão agrícola restrita, por conta de processos erosivos e integrado a isso, as maiores declividades do município, encontram-se nesta localidade. Fato este que além de acelerar o processo erosivo, não se recomenda o plantio da cana em área com declividade maior que $12 \%$, pois este já não se torna apto à mecanização, que será utilizada na colheita da cana à médio/longo prazo.

A área do bairro rural Zimaré São Paulo/Paraná, onde há uma grande concentração de pequenas propriedades, grande parte de proprietários idosos, que hoje sobrevivem com 0 recebimento de aposentadoria (FUNRURAL). Esta área a curto/médio prazo, tende a ser vendida ou arrendada pelo herdeiros à usina de álcool, passando a partir da aglutinação de pequenas propriedades, a se cultivar cana-de-açúcar nesta área.

A localidade referida está inserida uma área remanescente da antiga fazenda São Paulo/ Paraná, caracterizado como uma grande propriedade com pastagens, milho e uma área com cultivo de café. Em entrevista realizada com o atual proprietário, se constatou a iniciativa deste de estar arrendando as terras junto à usina de álcool Copagra para o cultivo da cana-de-açúcar.

Foi destacada outra localidade, onde demonstram as áreas de preservação permanente (APP) e as áreas de reserva legal (RL), procurando representar as áreas de $R L$ já constituída dentro do município e as APP de mata ciliar, obedecendo a legislação vigente de se reservar 30 metros para ambas às margens do rio (dentro da configuração de corpo hídrico presente no município) para constituição de mata ciliar e de 50 metros para as áreas de nascentes, sendo estas áreas em médio/longo prazo, totalmente em conforme com a legislação vigente, representando assim, um grande avanço para a sustentabilidade ambiental do município.

A partir desse momento é possível expor algumas considerações sobre a dinâmica de uso e ocupação do solo ocorrido no município.

A primeira delas é a de que 0 avanço da cana-de-açúcar no município tende a ser junto à média/grande propriedade onde antes praticava a cultura da mandioca e/ou pastagem, não promovendo este avanço, impacto ambiental, no que se diz a abertura de novas áreas por meio de desmatamentos.

Com este prognóstico de uso e ocupação do solo já desenvolvido, parte-se para uma segunda etapa, que é o prognóstico dos impactos sociais destas dinâmicas

A diminuição do número de habitantes da zona rural aconteceu entre os períodos de $1970 \mathrm{e}$ 1990, sendo que a partir deste ano, ocorreu seu incremento. Com o desenvolvimento massivo da cultura da cana-de-açúcar no município, é possível prognosticar uma estabilização do número de

Geografia Ensino \& Pesquisa, v. 16, n.2 p. 117 - 128, maio/ago. 2012

Abordagem dastransformações sócio-espaciais no município de Itaúna do Sul-PR a partir do modelo GTP habitantes, podendo até ocorrer incremento desta, porém para área urbana tendo como parâmetro que os cortadores de cana do município, moram em sua grande maioria, no perímetro urbano de Itaúna do Sul, e podendo haver perda de populacional da zona rural.

A perda da população rural dá-se em um primeiro momento pelo arrendamento de terras e aglutinação de pequenas propriedades para o plantio da cana-de-açúcar. Propriedades estas atualmente sob os cuidados de agricultores idosos, principalmente nas áreas do bairro rural Zimaré São Paulo/Paraná. Com relação a esta área, um prognóstico seria a manutenção desta pequena 
propriedade, associando a algum projeto (vaca leiteira, por exemplo) que não utilize grande mãode-obra, cena esta que deve durar até a passagem destas terras aos herdeiros, já em sua grande maioria, trabalhadores da cidade, sem apego à terra, que poderá estar vendendo esta propriedade ou arrendando para usinas de álcool da região.

Em um segundo momento, já com a expansão do plantio de cana-de-açúcar, a queimada do canavial utilizada no processo de colheita é um motivo de repulsa desta população já que há a impossibilidade de habitação próxima às áreas onde ocorrem estas queimadas. A queima da palha da cana-de-açúcar é extremamente danosa à saúde e ao meio ambiente. A queimada consiste em atear fogo no canavial para destruir cerca de $30 \%$ da biomassa (folhas secas e verdes), que não interessam à indústria do açúcar e do álcool além de facilitar o trabalho de corte da cana-de-açúcar.

A queima da palha libera gás carbônico e outros gases na atmosfera nocivos à saúde. Entre as substâncias químicas liberados destacam-se os HAPs (Hidrocarbonetos Aromáticos Policíclicos), componente altamente cancerígeno onde de acordo com estudo realizado pela Unesp (Universidade Estadual Paulista) de Presidente Prudente, foi constatado um aumento de HPAs no organismo dos cortadores de cana e no ar das imediações de canaviais durante a época de safra. Com base nesses dados é de se esperar um aumento da procura de atendimento médico pela população, com problemas relacionados principalmente ao sistema respiratório. Portanto cabe aos gestores tomar consciência, que para um prognóstico de curto prazo, haverá um aumento de verbas destinadas à saúde pública.

Para um prognóstico de médio prazo, mantendo-se as condições previstas anteriormente, poderá se iniciar novamente o processo de perda de população do município, pois as áreas prognosticadas para o avanço da cana-de-açúcar compreendem terrenos propícios à mecanização. O conceito de "área mecanizável" pode ser encontrado em diversos trabalhos como Ripolli (1992) e Sparovek (1997), e segue basicamente uma limitação topográfica. Segundo o conceito, terrenos com declividade superior a $12 \%$ não são passivveis de mecanização, em razão do aumento do percentual de perdas em matéria prima, e do risco que é exposta à máquina colhedora. Portanto, de acordo com a legislação vigente de substituição gradual de queimadas pelo uso da mecanização, proporcionará uma redução considerável do número de empregos para o corte da cana, transformando-se também em um grande problema social.

\section{Considerações finais}

O Noroeste paranaense tem passado, nos últimos 50 anos, por inúmeras transformações no âmbito social, econômico e ambiental. Isso tem dinamizado os processos e formas de uso e ocupação do território onde se deve tomar a devida atenção com a proteção dos recursos naturais, tão fragilizado pelo modo de ocupação e apropriação ocorrido neste território.

A cultura do algodão e principalmente a do café, foram propulsoras à ocupação do noroeste do Paraná, porém de forma não sustentável. Isso se deve, principalmente pela forma de divisão dos lotes rurais, pelo mercado externo muito instável e pelas sucessivas pragas e geadas que acabaram posteriormente, fragilizando a já decadente cultura do café do noroeste paranaense.

No momento atual, encontramos presente na região, a expansão da cana-de-açúcar, motivada principalmente por:

- princípio de troca da matriz energética do país;

- relatório do aquecimento global, relacionando o fato à emissão de $\mathrm{CO} 2$;

- mercado crescente do ETANOL;

- instalação de duas usinas sucro-alcooleiras : Santa Terezinha, no município de Terra Rica, e COPAGRA em Nova Londrina.

No município de Itaúna do Sul, quando houve a crise da cafeicultura, ocorreu um processo de desmonte de parte das grandes propriedades, que foram divididas em lotes menores onde hoje

Geografia Ensino \& Pesquisa, v. 16, n.2 p. 117- 128, maio/ago. 2012

Sant'ana, L. C. F.; Passos, M. M. 
há a prática da policultura em muitas propriedades, porém não há a sustentabilidade econômica ainda para este pequeno produtor, pois:

- idade avançada de grande parte dos pequenos produtores;

- descendentes em sua grande maioria não se encontram mais no município, ou os que ainda estão, trabalham no setor de serviços da área urbana;

- extensão da propriedade muito pequena, dificultando uma produção que seja mais competitiva no mercado;

- falta iniciativa de uma associação de pequenos produtores.

Com Relação ao prognóstico da área, é eminente o avanço da cultura da cana-de-açúcar no município de Itaúna do Sul, mesmo com a preocupação que existe por parte dos gestores municipais com este fato.

O desenvolvimento de políticas públicas voltadas ao pequeno produtor rural, em um primeiro momento, é capaz de gerar a sustentabilidade, porém na menor oscilação de rendimentos, este produtor rural acaba que cedendo à cultura canavieira, vendendo sua propriedade ou então a arrendando.

Portanto, se demonstraram importante as iniciativas da gestão pública municipal no fato de garantir a estabilidade fundiária no município e promover avanços na área ambiental, no que se diz na recuperação de APPs e RLs.

Porém, as políticas públicas de apoio ao pequeno produtor, entram em conflito com a política de expansão da cana-de-açúcar, com o incentivo de produção de etanol por parte do governo Federal, onde esta força apresenta muito mais capacidade de se concretizar e dinamizar o território do que as políticas públicas citadas anteriormente.

Cabe então à gestão pública não tornar-se inoperante frente a esta perspectiva mais sim, procurar gerar políticas públicas ao menos de redução dos danos gerados pelo avanço da cana-de-açúcar no município.

\section{Referências}

BECKER, Dinizar Fermiano (org). DESENVOLVIMENTO SUSTENTÁVEL: NECESSIDADE E/OU POSSIBILIDADE. $3^{\text {a }}$ ed. Santa Cruz do Sul: EDUNISC, 2001.

BERTRAND, G. ; BERTRAND, Claude Le géosysstème: un espace-temps anthropisé. Esquisse d'une temporalité environnementale. Revue géographique des Pyrénées et du Sud-Ouest. Toulouse, v. 75, n. 2 p. 65-75, 1999.

Paisagem e Geografia Física Global. Esboço Metodológico. Caderno de Ciências da Terra, Revista do DG. São Paulo: FFLCH/USP, n¹3, p. 1-27, 1972.

CRESTANA, Sílvio. Harmonia e respeito entre homens e a natureza: uma questão de vida - a contribuição da agrucutura. . Desenvolvimento Sustentado: Problemas e Estratégias, p.199-213. Elisabete Gabriela Castellano - editora, 1997.

Geografia Ensino \& Pesquisa, v. 16, n.2 p. 117 - 128, maio/ago. 2012

Abordagem dastransformações sócio-espaciais no município de Itaúna do Sul-PR a partir do modelo GTP
ENDLICH, Ângela Maria. Formação Socioespacial da Região Noroeste do Paraná e as Pequenas Cidades. BOLETIM DE GEOGRAFIA. Universidade Estadual de Maringá- Departamento de Geografia, Maringá. ANO 25 número I, p. 37- 58, 2007.

LEME, R. C. B. DESENVOLVIMENTO E MEIO AMBIENTE: Uma avaliação das políticas públicas na mesorregião sudoeste do Paraná. 2007. Tese de doutorado. Programa de Pós-graduação em Geografia. Universidade Estadual Paulista. Presidente Prudente. 
PASSOS, Messias Modesto dos. Uma Geografia Transversal - e de travessias - (0 meio ambiente através dos territórios e das temporalidades). Maringá: Editora Massoni, 2007.

RIBEIRO, Matheus A. G. A Paisagem, uma ferramenta de análise para o desenvolvimento sustentável de Territórios emergentes na Interface entre natureza e sociedade. 2009. Dissertação de mestrado. Programa de Pós-graduação em Geografia, Universidade Estadual de Maringá. Maringá.

TONIOLO, M. L. S. As Obras Compensatórias e Mitigatórias da UHE de Rosana. Município de Terra Rica - Noroeste do Paraná. 2006. Dissertação de Mestrado. Programa de Pósgraduação em Geografia, Universidade Estadual de Maringá. Maringá.

\section{Correspondência:}

Lucas César Frediani Sant' ana - Universidade do Estado do Rio Grande do Norte/ CAMEAM/ UERN

BR 405 sem número. Bairro Arizona - Pau dos Ferros, RN. CEP: 59.900-000

E-mail: lucas.geografia@gmail.com

Recebido em 30 de agosto de 2011.

Revisado pelo autor em 28 de janeiro de 2012.

Aceito para publicação em 18 de julho de 2012. 